\title{
Massive Obscure Overt Gastrointestinal Bleed: An Unusual Cause diagnosed by Capsule Endoscopy
}

\author{
Chalapathi Rao, Aman Sharma, Surinder S Rana, Amit Bhauwala, Surjeet Singh, Kartar Singh, Deepak K Bhasin
}

\begin{abstract}
Common causes for obscure overt gastrointestinal bleeding originating from the small bowel include small bowel angioectasias, Crohn's disease, ulcers and tumors. In tropical countries, intestinal ulcerations secondary to tuberculosis and parasitic infestations have also been described as causes of gastrointestinal bleeding. We present a very unusual case of massive obscure overt gastrointestinal bleeding due to massive hookworm infestation of the small bowel that was diagnosed by capsule endoscopy and successfully treated with oral albendazole.
\end{abstract}

Keywords: Hookworm, Obscure gastrointestinal bleed, Wireless capsule endoscopy, Albendazole.

How to cite this article: Rao C, Sharma A, Rana SS, Bhauwala A, Singh S, Singh K, Bhasin DK. Massive Obscure Overt Gastrointestinal Bleed: An Unusual Cause diagnosed by Capsule Endoscopy. J Postgrad Med Edu Res 2012;46(1):37-39.

Source of support: Nil

Conflict of interest: None declared

\section{INTRODUCTION}

The inception of wireless capsule endoscopy into the diagnostic armamentaria of obscure gastrointestinal bleeding (GIB) made noninvasive visualization of the small bowel much easier. Apart from the common small bowel angioectasias, Crohn's disease and tumors, unusual etiologies for obscure GIB like worm infestation and intestinal tuberculosis were being picked up using small bowel endoscopy in tropical countries. It helps in exact localization of the bleeding lesion and helps in further endoscopic or surgical management. We present a case of massive GIB due to hookworm infestation diagnosed on wireless capsule endoscopy (WCE).

\section{CASE REPORT}

A 25-year-old male patient with no previous comorbidities or drug abuse, presented with acute onset of GIB in the form of multiple bouts of hematemesis and melena for a week before presentation to our hospital. He denied any abdominal pain, jaundice, abdominal distension or encephalopathy. He received 2 units of blood transfusion of packed red cells outside before getting referred to our center. Examination revealed pallor and tachycardia. His abdominal, cardiac and respiratory examination did not reveal any significant abnormality. At admission, he had hemoglobin of $4.8 \mathrm{gm} \%$ with normal total leukocyte and platelet counts. Renal and liver function tests and electrolytes were normal as was his coagulation profile. His ultrasound examination of abdomen showed normal liver, spleen and portal vein. There was no free fluid. Upper gastrointestinal endoscopy was normal. Colonoscopy revealed fresh and altered blood coating the mucosa of entire length of colon and terminal $5 \mathrm{~cm}$ of ileum but a specific cause for bleed could not be identified. There was no significant source of bleed identified on contrast-enhanced computed tomographic (CECT) scan of abdomen and barium meal follow through (BMFT). 99mTechnetiumlabeled red blood cell scintigraphy showed a probable source of active bleeding from cecum and ascending colon. He received 2 units of packed red cell transfusion in hospital. An option of surgical exploration with intraoperative enteroscopy was discussed. A stool routine examination showed ova of hookworm. Single course of $400 \mathrm{mg}$ of oral albendazole was given to the patient. Meanwhile, patient underwent a WCE examination of small bowel after stabilization to look for a definite source of bleed. There were numerous hookworms noted on WCE (Fig. 1) in the whole of the small bowel. No other source of GIB was noted. A $400 \mathrm{mg}$ dose of tablet albendazole was repeated in view of high worm load. Patient was asymptomatic with no recurrence of GIB repeat stool examination did not reveal any ova or cysts. He has been asymptomatic over a follow-up period of 6 months and his hemoglobin has improved to $11.2 \mathrm{gm} \%$.

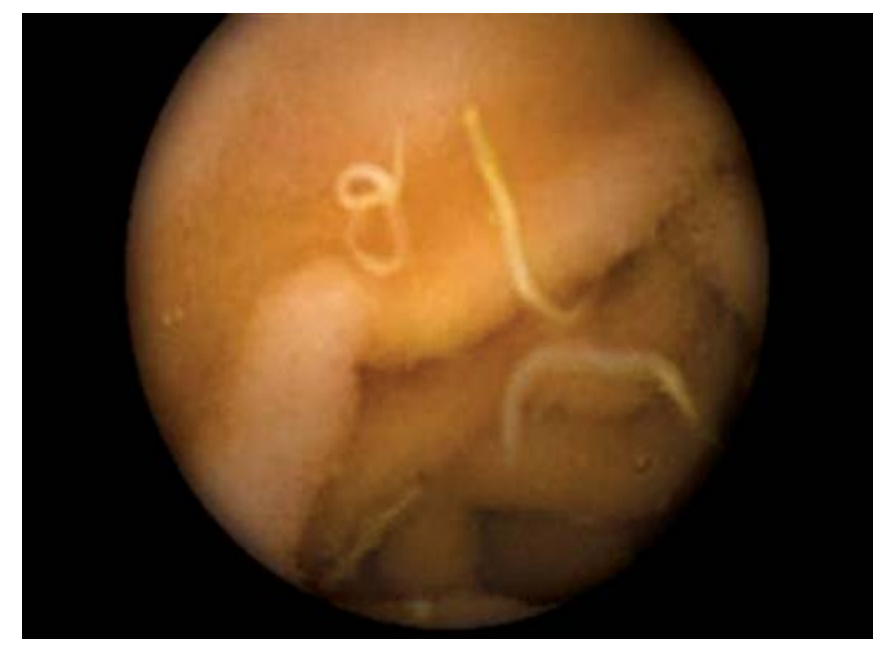

Fig. 1: Wireless capsule endoscopy showing numerous hookworms floating in the intestinal lumen after a course of oral albendazole 


\section{DISCUSSION}

Two hookworm species [Necator americanus (predominantly in southern India), Ancylostoma duodenale (predominantly in northern India)] are responsible for human infections. ${ }^{1}$ Worldwide, an estimated 740 million people are infested with hookworm. ${ }^{2}$ The worms inhabit the small bowel and graze on the blood and interstitial fluid. An adult worm sucks blood at the rate of 0.01 to $0.3 \mathrm{ml} /$ day depending on the species infections. ${ }^{1}$ Depending on the worm burden, duration of infection and iron stores in the body, the manifestations may range from clinically asymptomatic to chronic blood loss and symptomatic iron deficiency anemia. Identification of 40 by $60 \mu \mathrm{m}$ oval hookworm eggs in the feces helps in the definitive diagnosis. Repeated stool examinations on three separate samples may increase the yield of diagnosis. ${ }^{3}$ Occasionally, hookworms may be identified on endoscopic examination, wherein, tiny motile worms may be seen attached to the small bowel mucosa with surrounding erosions, ooze of blood or hyperemia. ${ }^{4}$ The major advantage of endoscopy over stool examination is that it may detect other lesions causing GIB and obviates the need to wait for the results of 3 to 6 consecutive stool samples. Moreover, stool examination may be normal in up to $40 \%$ of cases. ${ }^{5}$

In our patient, hookworm infestation has caused massive overt GIB. Massive GIB due to hookworm infestation is a rare entity. It is commonly seen in pediatric age group and has been rarely reported in adult population. ${ }^{6}$ The severity of blood loss depends on the magnitude of the worm burden and the acuteness of the infestation. Occult bleeding may be the only manifestation in chronic infestation but massive GIB with grossly tarry stools may be seen in acute heavy infestation.

Since its advent, WCE has been consistently shown to have incremental yield over push enteroscopy and small bowel radiography. It has been recommended as the third study of choice in the evaluation of obscure GIB after bidirectional endoscopy. ${ }^{7}$ In a recent series by Ghoshal et al, ${ }^{8}$ hookworm infestation alone, identified on WCE, has been attributed as the cause of overt obscure GIB in four patients. Similarly, Gupta et al diagnosed a single of hookworm infestation on WCE among 154 patients with obscure GIB. ${ }^{9}$ We too had an experience in identifying hookworm infestation on gastroscopy. ${ }^{10}$ Oral albendazole (400 mg once) and mebendazole (100 mg twice daily for 3 days) are the usual antihelminthics available for effective treatment. Oral iron supplements (for iron-deficiency anemia) and nutritional support (for protein malnutrition) may also be required in symptomatic disease.

\section{CONCLUSION}

Hookworm infestation should be considered as the etiology for obscure overt gastro-intestinal bleed, even if it massive, especially in tropical countries.

\section{REFERENCES}

1. Feldman M, Friedman LS, Brandt LJ. Sleisenger and fordtran's gastrointestinal and liver disease: Pathophysiology/diagnosis/ management. Philadelphia: Saunders Elsevier publications; 2010.

2. Bethony J, Brooker S, Albonico M, et al. Soil-transmitted helminth infections: Ascariasis, trichuriasis, and hookworm. Lancet 2006;367:1521-32.

3. Knopp S, Mgeni AF, Khamis IS, et al. Diagnosis of soiltransmitted helminths in the era of preventive chemotherapy: Effect of multiple stool sampling and use of different diagnostic techniques. PLoS Negl Trop Dis 2008;2:e331.

4. Sharma BC, Bhasin DK, Bhatti HS, Das G, Singh K. Gastrointestinal bleeding due to worm infestation, with negative upper gastrointestinal endoscopy findings: Impact of enteroscopy. Endoscopy 2000;32:314-16.

5. Pawlowski ZS. Ascariasis. Clin Gastroenterol 1978;7: 157-78.

6. Laosombat V, Thiravibul K, Premasathian D. Massive intestinal hemorrhage leading to exploratory laparotomy in child with hookworm infection. Southeast Asian J Trop Med Public Health 1980;11:269-72.

7. Raju GS, Gerson LB, Das A, et al. American Gastroenterological Association (AGA) technical review on obscure gastrointestinal bleeding. Gastroenterology 2007;133:1697-717.

8. Ghoshal UC, Lakshmi CP, Kumar S, Das K, Misra A, Rai P, Mohindra S, et al. Capsule endoscopy for obscure gastrointestinal bleeding in the tropics: Report from India. Digestive Endoscopy 2011;23:17-23.

9. Gupta R, Lakhtakia S, Tandan M, Banerjee R, Ramchandani M, Anuradha S, Ramji C, et al. Capsule endoscopy in obscure gastrointestinal bleeding_an Indian experience. Indian J Gastroenterol 2006;25:188-90.

10. Rana SS, Bhasin DK, Sinha SK. Endoscopic diagnosis of chronic severe upper GI bleeding due to helminthic infection. Gastrointest Endosc 2008;68:1023.

\section{ABOUT THE AUTHORS}

\section{Chalapathi Rao}

Pool Officer, Department of Gastroenterology, Postgraduate Institute of Medical Education and Research, Chandigarh, India

\section{Aman Sharma}

Assistant Professor, Department of Internal Medicine, Postgraduate Institute of Medical Education and Research, Chandigarh, India

\section{Surinder S Rana (Corresponding Author)}

Assistant Professor, Department of Gastroenterology, Postgraduate Institute of Medical Education and Research, Chandigarh, India e-mail: drsurinderrana@yahoo.co.in, sonalisurinder@yahoo.co.in 


\section{Amit Bhauwala}

Junior Resident, Department of Internal Medicine, Postgraduate Institute of Medical Education and Research, Chandigarh, India

\section{Surjeet Singh}

Professor, Department of Internal Medicine, Postgraduate Institute of Medical Education and Research, Chandigarh, India

\section{Kartar Singh}

Professor, Department of Gastroenterology, Postgraduate Institute of Medical Education and Research, Chandigarh, India

\section{Deepak K Bhasin}

Professor, Department of Gastroenterology, Postgraduate Institute of Medical Education and Research, Chandigarh, India 